\title{
Environmental risk factors for cancer - review paper
}

\author{
Anna Maria Lewandowska, ${ }^{1, A, C-D}$, Marcin Rudzki ${ }^{2, B-C}$, Sławomir Rudzki ${ }^{3, E-F}$, \\ Tomasz Lewandowski ${ }^{4, B-C}$, Barbara Laskowska ${ }^{1, D}$ \\ ${ }^{1}$ Institute of Healthcare, State School of Technology and Economics, Jaroslaw, Poland \\ ${ }^{2}$ Chair and Department of Jaw Orthopaedics, Medical University, Lublin, Poland \\ ${ }^{3}$ I Chair and Department of General and Transplant Surgery and Nutritional Medical University, Lublin, Poland \\ ${ }^{4}$ Institute of Technical Engineering State School of Technology and Economics, Jaroslaw, Poland \\ A - Research concept and design, B - Collection and/or assembly of data, C - Data analysis and interpretation, \\ $D$ - Writing the article, E-Critical revision of the article, F - Final approval of article
}

Lewandowska AM, Rudzki M, Rudzki S, Lewandowski T, Laskowska B. Environmental risk factors for cancer - review paper. Ann Agric Environ Med. 2019; 26(1): 1-7. doi: 10.26444/aaem/94299

\section{Abstract}

The cancerous process is result of disturbed cell function. This is due to the accumulation of many genetic and epigenetic changes within the cell, expressed in the accumulation of chromosomal or molecular aberrations, which leads to genetic instability. It is difficult to assess the validity of individual aetiological factors, but it can be concluded that interaction of various risk factors has the largest contribution to the cancer development. Environmental, exogenous and endogenous factors as well as individual factors, including genetic predisposition contribute to the development of cancer. Epidemiological research on the development of malignant tumors has focused over the years on the determinants of environmental and genetic factors of cancer incidence and mortality rate. According to current state of knowledge, $80-90 \%$ of malignant tumors are caused by external environmental factors (carcinogens). Epidemiological studies have proved that the main factors responsible for the development of malignant neoplasia among humans are environmental factors arising from human behaviour. It has been confirmed that smoking, excessive alcohol consumption, diet, and reproductive behaviour are important for the development of malignant neoplasia in the human population. According to the World Health Organization, in 2020 we may expect about 10 million deaths, including 7-8 million in the developing countries, while this number in the developed countries will not change and will be 2-3 million. The aim this study was systematization of knowledge concerning the risk factors of malignant tumours and supplementing them with the latest research results.

\section{Key words}

cancer, risk factors, environment, biological factor

\section{INTRODUCTION}

Cancer is the cause of approx. 90.000 deaths and 12.000 new cases annually in the world. They are the main cause of premature mortality in the Polish population in young and middle-aged people (aged 20-64), one of the highest in the world, and the most common cause of death among women between the ages of 20-64. During the span of 40 years, there was a two-fold increase in mortality in women and threefold in men. Morbidity and mortality caused by cancer are mainly due to changes in exposure to risk factors. According to the World Health Organization, more deaths worldwide are caused by cancer than by cardiovascular diseases. More than 20 million new cases of cancer are predicted to appear before 2025, especially in low- and middle-income countries. Epidemiological evidence of cancer can be divided into two categories: the first, which can be described as accidental, comes from the interpretation of perceived differences in gender, age, socio-economic conditions, and the second category of evidence derived from analytical studies, deliberately planned in order to check the hypotheses suggested by the first category $[1,2,3]$.

Address for correspondence: Anna Maria Lewandowska, Institute of Healthcare, State School of Technology and Economics in Jaroslaw, Poland, ul. Pasieka 21F, 37-500 Jarosław, Poland

e-mail: am.lewandowska@poczta.fm

Received: 29.12.2017; accepted: 14.08.2018; first published: 17.10.2018
The cancerous process is a result of disturbed cell function. This is due to the accumulation of many genetic and epigenetic changes within the cell, expressed in the accumulation of chromosomal or molecular aberrations, which leads to genetic instability $[4,5,6]$. It is difficult to assess the validity of individual aetiological factors, but it can be concluded that interaction of various risk factors has the largest contribution to the cancer development. Environmental, exogenous and endogenous factors, as well as individual factors, including genetic predisposition, contribute to the development of cancer $[7,8,9]$.

According to the WHO research, 35\% of deaths caused by cancer worldwide are due to potentially modifiable risk factors resulting from lifestyle, including smoking and alcohol consumption, in countries with low, medium and high incomes, infections, parasites, exposure to ultraviolet light and tanning using devices that emit ultraviolet radiation, environmental tobacco smoking, dietary factors, hormone replacement therapy, as well as exposure to ionizing radiation $[4,10,11,12]$.

\section{MATERIALS AND METHOD}

To review the evidence, use was made of a PubMed search which included articles published between 2010-2018. Combinations of the following key words were used: 'cancer 
risk factors', 'cancer environmental factors', 'physical factors causing cancer', 'chemical factors causing cancer', 'biological factors causing cancer', 'infections causing cancer' (key words: cancer, risk factors, environmental factors of cancer) to review the evidence. From this search, a total of 1,545 potentially relevant articles were identified. This number was reduced to 64 articles after screening titles and abstracts for relevance to the current review by two independent reviewers. The articles were in English and Polish. After compiling a list of potentially relevant articles, the full text of each paper was appraised, with particular emphasis on articles presenting environmental risk factors for cancer. This was for the purpose of more extensively presenting study characteristics and results in order to present the information from each article allowing the reader a more thorough assessment of the current literature and to draw interpretations and final conclusions.

\section{OBJECTIVE}

Systematization of knowledge concerning the risk factors of malignant tumours and supplementing them with the latest research results.

\section{RESULTS}

\section{Physical factors}

Exposure to electromagnetic fields. In 1979, based on epidemiological studies, Wertheimer and Leeper proved an increased risk of leukemia among 'American children living in homes with higher than average intensity of magnetic fields'. Based on these reports, in 1998 a group of experts from the US National Institute of Environmental Health Science found that there is limited evidence that exposure to magnetic field is carcinogenic. The World Health Organization (EMF-WHO) in a monograph of the International Programme 'Electromagnetic Fields' considers a magnetic field of $50 / 60 \mathrm{~Hz}$ a probable tumour factor [13, $14,15,16]$. There are also data from epidemiological studies indicating a relationship between exposure to a low frequency magnetic field (0-300 Hz) and risk of breast cancer. A 6.5fold increased risk of breast cancer was detected among technicians of a telecommunication company in New York, as well as among women living within a radius of $300 \mathrm{~m}$ from power lines in Sweden, where 'relative risk associated with exposure to fields with induction value above $0.1 \mu \mathrm{T}$ was more than doubled'. At the current stage of research, there is consensus that in children living in conditions where the magnetic field strength exceeds $0.4 \mu \mathrm{T}(4 \mathrm{mG})$, the risk of leukemia increases twice, but there is no evidence showing if these fields are its causative factor [15].

Ionizing radiation. One of the most commonly mentioned carcinogens is ionizing radiation which may induce tumours in all organs where the cancer appears spontaneously [3, 17]. First reports on the harmfulness of ionizing radiation appeared in the mid-twentieth century following the observations of children who had survived atomic bomb explosions in Hiroshima and Nagasaki, as well as children who had undergone prenatal RTG. An increased risk of leukemia and thyroid cancer was detected [8]. It was found that diagnostic radiology performed on pregnant women increased the risk of childhood cancers. This risk is dependent on the radiation dose and the number of exposures. Literature reports that the percentage of all cancers attributed to radiation is $2-3 \%$, and children exposed to X-rays most often develop liver cancer, bone cancer and leukemia. The need for radiotherapy in the case of already existing childhood cancers significantly increases the risk of secondary cancers $[3,17]$. When higher doses of radiation are used during brain tumour therapy, there is an increased risk of developing gliomas and glial tumours, while women who have undergone radiation therapy of a malignant tumour of the chest during their childhood are more likely to develop breast cancer. As demonstrated in research, the risk of breast cancer begins to increase about eight years after exposure to radiation, and cancer often develops before the age of 40 [17]. Ionizing radiation may also stimulate neuroplasia in the case of penetrating irradiation of the thyroid gland (thyroid carcinoma), chest (lung cancer) and bladder (malignant bladder tumours). Radiation therapy used in childhood stimulates carcinogenesis in the gastrointestinal tract and the risk of further malignant gastrointestinal cancers is significantly higher than in the general population [17].

Ultraviolet radiation. Ultraviolet radiation is the most common environmental factor affecting the skin, while ultraviolet radiation is mainly responsible for its harmful properties [18]. Chronic and excessive exposure to sunlight often leads to adverse early-onset effects, such as erythema or sunburn, and late symptoms of accelerated skin aging and even post-solar carcinogenesis. It has been proved that excessive exposure to ultraviolet radiation significantly increases the risk of pigmentary and non-pigmentary skin cancers - melanoma and squamous skin carcinoma $[19,20]$. UVB (ultraviolet shortwave) radiation with a wavelength of $280-315 \mathrm{~nm}$ represents $5 \%$ of the UV radiation reaching the surface of the earth, the rest is UVB radiation [18]. Accumulation of DNA damage by UV rays is mutagenic in a complex way, on the one hand it damages the pathways leading to apoptosis of damaged cells an on the otherpromotes the proliferation of altered, immature cells. Under the influence of UV radiation, the 'formation of pyrimidine dimers - thymidine dimers or thymine dimers with cytosine and 6,4-photoproducts causes damage to the DNA of epidermal cells' [20]. Direct mutagenic effects and local immunosuppression in the skin is mainly caused by $\mathrm{UVB}$ radiation, which is about 1000 times more mutagenic than UVA' (ultraviolet long wave radiation); however, UVA indicates direct damage to cellular DNA [20, 21, 22, 23, 24]. Also solarium shows its carcinogenic effects. The emitted UVA radiation doses of tanning lamps far exceed doses to which skin is vulnerable when exposed to sunlight, which may cause defects in the defence mechanisms. Scientific studies on the effect of artificial UV radiation on skin cancer have shown that frequent, prolonged use of a solarium increases the risk of melanoma and squamous skin carcinoma. As a result of numerous studies, in 2009 the International Agency for Research on Cancer classified the radiation emitted by solarium lamps as a carcinogenic factor in relation to skin cancers, as well as other carcinogens, such as arsenic compounds, coal tar and soot [22, 23, 24, 25]. It is disturbing that using a solarium and excessive sun exposure are common among young people who easily succumb to the 
'fashionable' and attractively presented in mass media image of tanned skin. [20].

\section{Chemical factors}

Tobacco smoking. Worldwide, tobacco use is the largest avoidable risk factor for death caused by cancer - it causes the deaths of around 6 million people every year. According to the WHO FCTC, all tobacco products, wholly or partly made of tobacco leaves used for smoking, chewing or sniffing, are sources of various carcinogens and other toxic factors. Some carcinogens are ingreidients of the tobacco plant itself, including nitrosamines [TSNA], N-nitrosonornicotine [NNN], 4-(methylnitrosamino)-1-(3-pyridyl)-1-butanone $[\mathrm{NNK}]$ ), most of which are formed when tobacco is burned (i.e. polycyclic aromatic hydrocarbons [PAHs], specifically benzo[a]pyrene. The processing, preservation and storage of tobacco may also cause the formation of carcinogens, i.e. volatile aldehydes, including acetaldehyde and formaldehyde, and TSNA) [26, 27, 28, 29]. More than 70 components of tobacco smoke are considered to be carcinogens to laboratory animals or humans, according to the International Agency for Research on Cancer (IARC), and 16 of them are recognized as carcinogenic for humans. The strongest activity is demonstrated by: benzene, dimethylnitrosamine, ethylmethyltitrosamine, diethylnitrosamine, nitrosopyrrolidine, hydrazine and vinyl chloride. A number of cocarcinogens have also been found, i.e. substances that have no carcinogenic properties, but which enhance the neoplastic process even with trace amounts of particular carcinogens. These include e.g. formaldehyde, pyrene, fluoranthene, naphthalenes and catechol [26, 30, 31]. Report from the United States National Cancer Institute and the Centers for Disease Control and Prevention shows that over 300 million people worldwide are smokeless users of tobacco products, stressing that most of them live in Southeast Asia, where oral cancer rate is the highest in the world [32]. Cigarette smoking is the most harmful form of tobacco use, the single and one of the most important causes of cancer. Research conducted by the American Cancer Society shows that tobacco smoking is causally related to at least 16 types of cancer. IARC classified smoking as the cause of haematopoietic tumours, larynx, squamous cell carcinoma of the mouth, throat cancer, bronchitis, esophagus, pancreas, kidney, bladder, lung cancer, large intestine, nasal cavity and paranasal sinuses, oesophagus, stomach, pancreas, liver, bladder, and cervical cancer. There is also evidence showing that smoking can cause breast cancer and leukemia in children $[26,30,33]$. Passive smoking is also carcinogenic, the smoke rising from the glowing tip of the cigarette is four times more harmful than that inhaled by the smoker. In a smoky room, a non-smoker inhales three times more carbon dioxide, over 10 times more nitrosamines, 15 times more benzene and up to 70 times more ammonia than active cigarette smokers. Passive smoking increases the risk of lung cancer by a quarter, increases the risk of laryngeal and oesophageal cancer as well as of childhood leukemia and cancer of the larynx, throat, brain, bladder, anus and stomach (American Cancer Society Report). It is also harmful to stay in rooms polluted with tobacco smoke; the gaseous remains of smoked cigarettes are deposited on the surfaces of furniture and fabrics, and become a component of dust. substances contained in tobacco smoke sediments still chemically active and harmful to health $[26,34,35]$.
Various studies have been carried out in order to assess the impact of both active and passive smoking on health and the risk of developing cancer. In a study conducted in the United Kingdom, the relative risk of malignant tumours among the children of women who smoked five or more cigarettes a day during pregnancy, was 2.5 (95\% CI 1.2-5.1). A study conducted in Sweden showed that there was a statistically increased risk of acute lymphocytic leukemia among the children of women who smoked during pregnancy. In the meta-analysis conducted by Boffetta et al., the relative risk of total malignancy in children of women who smoked during pregnancy was 1.1 (95\% CI 1.3-1.19), the relative risk for malignant tumours of the haematopoietic and lymphoid tissues was 1.03 (95\% CI 0.9-1.2), for non-Hodgkin's lymphoma and other lymphomas 1.1 (95\% CI 0.9-1.5), for central nervous system malignancies 1.04 (95\%) CI 0.921.18), while for leukemias - 1.1 (95\% CI 0.8-1.3) [36, 37].

A very worrying phenomenon is also passive exposure to tobacco smoke, the scale of which is huge in Poland. Every day, about four million Polish children passively smoke tobacco at home or in public places. In $2007,48 \%$ of adult Poles admitted that they either smoked or had been smoking in the presence of children, and $27 \%$ that they also did so in the presence of pregnant women. $[38,39]$ Becher and Wahrendorf (1994) in their studies estimated that about 400 deaths from lung cancer annually are caused by passive smoking. The latest meta-analysis of the US Department of Health and Human Services in 2006, and recent studies by Kim et al. in 2014, indicate that the relative risk of lung cancer due to passive smoking is 1.21 (95\% CI 1.14-1.28), for men $-7.66 \%$ and for women $-4.70 \%$ [2].

Alcohol. Epidemiological studies have indicated that there is a causal connection between alcohol consumption and an increased risk of cancer. Alcohol consumption increases the risk of cancer of the mouth, throat, larynx, esophagus, liver and breast $[40,41,42]$. The magnitude of the risk varies and depends on the amount of alcohol consumed, its type and other factors; even small amounts may increase the risk of cancer. Some studies have shown that having one alcoholic drink a day (6-8 g of pure ethanol) raises the risk of breast cancer by $11 \%$, whereas two drinks a day increase the risk of colorectal cancer by $8 \%$. The International Agency for Research on Cancer (IARC) has identified alcohol as a Class I carcinogen for liver cancer $[41,42]$. Consumption of alcohol, both high and low (10-12\%), is a risk factor for cancer. One portion of pure alcohol (10 g) per day for women, i.e. one glass of wine, a glass of beer or a small glass of strong alcohol, is considered acceptable and relatively safe. A portion is $30 \mathrm{ml}$ of vodka (40 per cent/vol), $100 \mathrm{ml}$ of wine (12 per cent/vol.), $285 \mathrm{ml}$ of strong beer (4.9 per cent/vol.) or $375 \mathrm{ml}$ of light beer. (3.5 per cent/vol.) For men, the acceptable daily intake is twice as high $[9,40,42]$. Alcohol enhances neoplasia by acting 'directly on the mucous membrane, eliminating the lipid component of the barrier that surrounds the granularity of the epithelial layer, or indirectly, by impairing the detoxifying function of the liver'. Recent research has shown that systematic and long-lasting use of alcohol-based mouthwashes is a contributing factor in the development of head and neck cancers, regardless of habitual smoking and consumption of alcoholic beverages. Taking into account only cancers of the oral cavity, pharynx and larynx, using mouthwash with alcohol twice a day increases the risk of 
cancer more than tenfold in smokers, over five times for drinkers and nearly fivefold for non-drinkers [42]. In a Swedish study of 605 patients with squamous cell carcinoma within the head or neck, the risk of oral cancer was estimated at consumption of more than $50 \mathrm{~g} / \mathrm{d}$ of pure alcohol for $\mathrm{RR}=5.7$ (95\% CI=2.8-11.9). The probability of throat cancer was estimated for $\mathrm{RR}=8.5$ (95\% $\mathrm{CI}=4.0-18.1)$. According to some researchers, drinking wine is the most important of all risk factors. In a study conducted by Franceschi et al., it was shown that consumption of beer and spirits does not increase the risk of oral cancer, contrary to consumption of wine. By consuming 35-55 glasses of wine per week (i.e. about 11 glasses of wine per day) the risk of cancer is $\mathrm{OR}=1.9$ (95\% CI=0.9-3.7). Identical risk values were obtained with respect to the presence of throat cancer [40,41]. Alcohol consumption increases the already high risk of mouth and throat, larynx and esophageal cancer in people who smoke. This effect appears to be synergistic, as the risk of cancer in these parts increases progressively with the increase in alcohol consumption by smokers. There are several mechanisms for this relationship: increased permeability of carcinogenic substances from tobacco smoke through the oral mucosa in the presence of alcohol; increased solubility of carcinogenic substances from tobacco smoke in ethanol; increased production of acetaldehyde from alcohol oxidation $[1,43,44]$.

Other chemicals. Children are often exposed to various chemicals used in the household, in agriculture and the environment, also development of civilization and associated increase in the occurrence of harmful substances are a cause of genetic mutation. Emissions of automotive exhausts, industrial pollutants and toxic industrial waste cause increased cancer incidence among children. High exposure to pesticides, smoke, incense or hair dye, as well as agricultural chemistry, may also increase the risk of cancer. Certain medications may also have carcinogenic effects: stilbestrol derivatives given in threatening abortions, aromatic benzene derivatives, chloro-organic substances, phenoxyacetic acid derivatives and myelosuppressive antibiotics $[45,46]$.

\section{Biological factors}

Diet. Incorrect diet is considered one of the main causes of malignant tumours. Because of the development of civilization, in the surrounding environment, also in the diet, there are numerous toxic substances that have a carcinogenic effect $[47,48]$. The World Cancer Research Fund Report 2007 estimates that 35\% of the incidences of cancer worldwide can be attributed to nutrition and lack of physical activity. Among these are: colorectal cancer, cancers of the breast, esophagus, stomach and pancreas. Dietary factors predisposing to their occurrence are: high energy intake and obesity, high fat intake, insufficient amount of dietary fibre, low calcium and vitamins intake and high sodium intake [49]. A poorly balanced diet leads to overweight and obesity which, as shown by the results of population studies, is becoming a serious epidemiological threat in developed countries. A correlation was found between overweight, body mass index and increased risk of cancer, particularly of the large intestine and breast. Epidemiological studies have shown that overweight and obesity, which are becoming a growing epidemic in most countries, are associated with increased risk of cancers in various localizations [39, 45]. In a 2002 monograph, the International Agency for Research on Cancer (IARC) presented the thesis that there is sufficient evidence to recognize overweight and obesity as the cause of esophagus, endometrium, kidney, colon and breast cancer. These studies were confirmed in 2007 by the World Cancer Research Fund (WCRF), which also declared that there is convincing evidence of the impact of obesity on the development of rectal, pancreatic and gallbladder cancer. Recent WCRF reports from 2014 and 2015 have added cancers of the ovaries and prostate cancers. The American Cancer Society estimates that among 1.5 million new cases of cancer diagnosed every year, at least $20 \%$ are the result of obesity. Epidemiological studies also show that obese patients treated oncologically have worse prognoses and greater mortality than patients with normal BMI $[48,50]$. The authors in their study have confirmed an increased risk of breast cancer in obese women compared to patients with normal weight. The risk was greatest in patients with $\mathrm{BMI}>35 \mathrm{~kg} / \mathrm{m}^{2}$, and compared with patients of average weight increased by $58 \%$. This regularity has been observed only in estrogen receprtor neoplasms [51]. Dietary factors indicated by the WCFR, which have a convincing or probable causal relationship with cancer, include insufficient intake of non-starchy vegetables, insufficient intake of fruit and vegetables, consumption of red and processed meat, insufficient intake of dietary fibre and excessive intake of salt $[52,53]$. Increased intake of red and processed meat is a factor that increases the risk of colon cancer. This is probably related to nitrites or nitrates used as preservatives, accumulation of heterocyclic amines and policyclic hydrocarbons during the thermal processing of meat, as well as large amounts of heme that stimulate the production of $\mathrm{N}$-nitroso compounds in the gastrointestinal tract, which may lead to cancer [50]. Other risk factors include deficiencies of vitamins, especially vitamin A, and iron, which may result in oral cancer. In some South American countries, the customary drinking of yerba mate is a risk factor [31]. Numerous data in the literature show that folic acid deficiency can be considered a factor increasing the risk of carcinogenesis [49]. An increasing amount of data concerning carcinogenesis of colorectal cancer and other dietdependent cancers regard the impact of insulin and insulinlike growth factor. Based on the results of the American community whose diet consists mostly of carbohydrates, it was found that there is a link between a high glycaemic index and increased risk of cancer $[49,50]$. The risk of cancer is also influenced by individual food products. Among the Japanese population who consume the largest amounts of rice, the risk of colorectal cancer was increased; a similar relationship was demonstrated in Australia in the case of high potato consumption, while in the American population consuming more snacks containing refined sugars, correlated positively with the risk of cancer [49]. Among the dietary factors that may have an oncogenic effect, high doses of nitrites and nitrates, salted, smoked and pickled food, as well as too greasy or too hot food, are considered important [50, 51]. The meta-analysis conducted by Huang [6] and the EPIC research suggest that a diet based on plant products reduces the risk of cancer by $18-40 \%$. The EPIC research proved that consuming large amounts of vegetables has a protective effect on the onset of cancer in patients with a positive family history; results of another part of the same study indicate that fatty acid intake is associated with an increased by approx. $13 \%$ risk of breast cancer $[7,8]$. Similar observations are 
shown by the Nurses' Health Study II (NSH II), in which over 44,000 women were observed for 15 years. The results indicate that increased meat intake in childhood and adolescence is associated with increased by $43 \%$ risk of premenopausal breast cancer. In addition, the results of another part of the NHS II (86,000 women observed for over 26 years) show a strong (20\%) reduction in breast cancer incidence in women consuming large amounts of fruit and vegetables $[48,39,52]$.

Physical activity. Among the factors contributing to the formation of tumours are also deficiencies or complete lack of physical activity. Recent reports show that physical activity can influence the risk of cancer through a variety of mechanisms. Deficiencies or lack of psychical activity lead to overweight which, in turn, increases the levels of circulating estrogens, androgens, insulin and insulin-like growth factors. These factors are related to the growth of cells as well as tumours. Reduced psychical activity also leads to increased exposure of breast tissue to circulating ovarian hormones, as well as to food retention in the large intestine, thus increasing the duration of the potential mutagenic effects on the intestinal lining. Evidence is constantly gathered which proves that physical activity directly and indirectly affects the risk of cancer; however, at the moment, knowledge on the subject is still insufficient $[30,53,54]$.

Mutagenic and carcinogenic compounds in food. Mutagenic and carcinogenic substances, depending on environmental factors, are present in various food products. These can be natural substances or formed as a result of food storage and processing. Most of them are classified as genotoxins, i.e. active forms of mutagen, which covalently bind to the DNA molecule, modifying the nitrogen basis, which leads to the synthesis of a protein with the substituted sequence. Mycotoxins are highly toxic, carcinogenic compounds produced by mould, mainly Penicillium, Asparagillus and Fusarium. Currently, about 400 mycotoxins have been identified, of which aflatoxins, ochratoxins, fumonisins and cearalenone are likely to be involved in the induction of breast, liver, esophagus and prostate cancer $[54,55]$. These belong to the strongest pollutants that appear mainly during the storage of numerous food products, most commonly in maize and peanuts $[47,56]$.

Nitrosoamines are compounds with strong carcinogenic properties, present in many food products, mainly in pickled meat and smoked fish, but also in beer, soy sauce and others. Studies on the adverse effect of nitrosamines have shown an association with gastric cancer $[47,56]$. Polycyclic aromatic hydrocarbons arise during incomplete combustion of organic matter and contain a condensed aromatic ring system. The most carcinogenic in this group are benzo[a]pyrene and benzo[a]antracene. These compounds are found in fresh vegetables, tea, smoked sausage and ham, but are also formed during baking, frying and smoking. Strong mutagenic effects are shown by roasted coffee, soluble and decaffeinated coffee, smoked fish and meat as well as meat dishes. These substances are also present in brandy and whisky $[47,56]$. Heterocyclic aromatic amines are potent mutagenic compounds produced during the thermal treatment of high protein food products. They are formed at $300^{\circ} \mathrm{C}$, which is why they can be found on the surface of fish and meat roasted on an open fire. In other high protein products, such as eggs, milk, cheeses and legumes, the presence of mutagens can be attributed to heat treatment which leads to a change in colour resulting from, inter alia, scab. Acrylamide is probably one of the human carcinogens produced during thermal treatment of foods high in starch, such as crisps, chips, coffee and bread $[47,56]$.

Infections. In the development of cancer, more and more attention is being paid to infectious agents that play a significant role in the aetiology of these diseases. Exposure to frequent infections continuously increases due to the accumulation of infectious agents in highly populated regions, and contact with animals that may be a reservoir of carcinogenic infectious agents $[3,46,57]$. Currently, a larger number of infectious agents that cause or contribute to certain cancers in humans has been identified [35, 42]. Epidemiological data show that Helicobacter pylori infections are associated with gastric cancer, C. pneumoniae with lung cancer, and Chlamydia trachomatis is a predisposing factor for the development of cervical cancer. Oncogenic properties have been documented in some human viruses. Epstein-Barr virus (EBV), causing nasopharyngeal carcinoma and Burkitt's lymphoma, has been identified in tumour cells; recent studies indicate EBV involvement in the ethiopathogenesis of gastric cancer, Hodgkin's lymphoma, as well as palatal tonsil and tongue cancer [31, $55,57]$. There are several potential mechanisms involved in the development of cholangiocarcinoma from Salmonella typhi, while streptococcus bovis is commonly associated with colorectal cancer. Infections by the Borrelia burgdorferi spirochete that causes lyme disease are also associated with lymphoma [35]. In addition, it has been shown that human herpesvirus type 8 (HHV8) is etiopathogenetically associated with Kaposi's sarcoma, which develops in acquired immune deficiency syndrome (AIDS) [31, 45, 46]. Another high-risk etiological factor is human papillomavirus (HPV) which has high affinity for cells of stratified squamous epithelium and mucous membrances. It is considered the main infectious cause of cervical cancer, and recently also of tongue and tonsils cancer. Infections with hepatitis B, C and D viruses (HBV, HCV, HDV) increase the risk of carcinogenesis due to the ease of inducing chronic infections, which may determine disturbances in the cell cycle regulation, leading to malignant transformation. Primary hepatocarcinoma in probably $80 \%$ of cases is associated with $\mathrm{HBV}[31,45,46]$. Cervical cancer is the second most common cancer in females worldwide. Human papillomavirus infecion is the most important factor in cervical cancer. Persistent infection caused by human papillomavirus types 16 and 18 contributes to over $90 \%$ of squamous and $75 \%$ of cervical adenocarcinoma. Currently, it is estimated that HPV types 16 and 18 are the most prevalent sexually transmitted virus [58, 59]. Identified human Merkel cell polyoma virus, human T-lymphotropic retrovirus type 1 (HTLV-1) and human immunodeficiency virus (HIV) type 1 and 2, that play a significant role in the epidemiology of leukemia, lung cancer and lymphomas. Parasitic infections also contribute to the formation of tumours: the main factor of gastric cancer being Schistosoma hematobium, and of bladder cancer - liver flukes. Opisthorchis viverinni and Clonorchis sinensis are important factors for cholangiocarcinomas and hepatocellular carcinomas in south-eastern Thailand and southern China [59, 60, 61]. 


\section{CONCLUSIONS}

In 2015, approximately 1.7 million Americans received a cancer diagnosis. 1 In 2030, this number will rise to nearly 2.3 million. Today, approximately two of three Americans will live for at least five years after being diagnosed with an invasive cancer. In addition, with care that aims to balance the effectiveness of treatment alongside the importance of quality of life, more patients than ever are not just living longer but are able to lead full lives. Yet, cancer remains a leading cause of death in the United States, and in 2015 claimed approximately 600,000 lives. On a global level, cancer is now one of the world's most pressing health challenges. Seven of every 10 cancer deaths occur in Africa, Asia, and Central and South America. By the year 2030, these cancer deaths could increase globally by as much as $80 \%$, according to WHO estimates $[62,63,64]$. The most commonly diagnosed cancers worldwide are those of the lung (1.8 million, $13.0 \%$ of the total), breast (1.7 million, $11.9 \%)$, and colorectum (1.4 million, 9.7\%). The most common causes of cancer death were cancers of the lung (1.6 million, $19.4 \%$ of the total), liver (0.8 million, $9.1 \%)$, and stomach (0.7 million, $8.8 \%)$.

Currently, it is known that environmental factors are the main threat of neoplastic changes. Some of epidemiological research suggests that the influence of environmental factors will further affect the cell's genetic material. This is connected with the spreading of carcinogens in various geographical zones. These are well-known and scientifically proven and may be modified; however, there are certain factors that cannot be fully controlled, such as industrialization, and are currently being tested for their influence on the human body. According to IARC data, one of many carcinogens known for a long time, but has a significant impact on the growth of cancer incidence around the world, is tobacco and its products which contain carcinogenic components of the plant itself, and substances resulting from processing and preservation.

Numerous cocarcinogens have also been found, i.e. substances that have no carcinogenic properties, but enhance the neoplastic process even with trace amounts of specific carcinogens. These include formaldehyde, pyrene, fluoranthene, naphthalenes and catechol [30-33]. A single risk factor that is more and more frequently described in the literature is alcohol which, as reported in the newest data, even in small doses has a strong carcinogenic effect, especially in people who simultaneously smoke tobacco due to the synergistic effect of these substances, increasing the solubility of carcinogenic substances from tobacco smoke in ethanol $[43,44]$. Many scientific data confirm the carcinogenic influence of diet on the human body, stressing the correlation between overweight, body mass index and cancer. However, according to the latest reports, the biggest threat is the every day diet, in which the insufficient intake of non-starchy vegetables, insufficient intake of fruit and vegetables, deficiency of folic acid, frequent consumption of red and processed meat, insufficient intake of dietary fibre and salt intake, have a carcinogenic effect [50-53]. Carcinogenic properties are also displayed by chemical compounds created during the proccessing of food, among others, nitrosamines, polycyclic aromatic hydrocarbons and acrylamide $[47,56]$.

The latest reports stress the role of infectious agents in the formation of tumours, especially due to increased exposure to frequent infections caused by the accumulation of infectious factors in large populations, as well as by contact with animals. In recent years, a significant role has been demonstrated in the epidemiology of Salmonella typhi, Streptococcus bovis, Human papillomavirus, Type 1 retrovirus (HTLV-1) or Borrelia burgdorferi. It is expected that in the future more causes of cancer will be due to infections, which display an increasing part in the process of carcinogenesis, and in $20 \%$ a share in the formation of cancer is attributed to them $[60,61]$.

\section{REFERENCES}

1. Ansell P, Johnston T, Simpson J, Crouch S, Roman E, Picton S. Brain Tumor Signs and Symptoms: Analysis of Primary Health Care Records From the UKCCS. Pediatrics. 2010; 125: 112-119, https://doi:10.1542/ peds.2009-0254.

2. Kim CH, et al. Exposure to secondhand tobacco smoke and lung cancer by histological type: a pooled analysis of the International Lung Cancer Consortium (ILCCO). Int J Cancer. 2014; 135(8): 1918-30. https://doi: $10.1002 /$ ijc. 28835

3. Sifri R, Gangadharappa S, Acheson LS. Identifying and testing for hereditary susceptibility to common cancers. CA Cancer J Clin. 2004; 54(6): 309-26.

4. Weiderpass E. Lifestyle and cancer risk. J Prev Med Public Health. 2010 Nov; 43(6): 459-71. doi: 10.3961/jpmph.2010.43.6.459.

5. Andersson TM, Engholm G, Brink AL, Pukkala E, Stenbeck M, Tryggvadottir L, Weiderpass E, Storm H. Tackling the tobacco epidemic in the Nordic countries and lower cancer incidence by $1 / 5$ in a 30-year period-The effect of envisaged scenarios changing smoking prevalence. Eur J Cancer. 2018; 29(18): 30239-9. https://doi: 10.1016/j. ejca.2018.02.031.

6. Huang T, Yang B, Zheng J, Wahlqvist ML, Li D. Cardiovascular disease mortality andcancer incidence in vegetarians: a meta-analysis and systematic review. Ann Nutr Metab. 2012; 60(4): 233-240, https://doi. org/10.1159/000337301.

7. Crowe FL, Appleby PN, Travis RC, Key TJ. Risk of hospitalization or death from ischemic heart disease among British vegetarians and nonvegetarians: results from the EPIC-Oxford cohort study. Am J Clin Nutr. 2013; 97(3): 597-603, https://doi.org/10.3945/ajcn.112.044073.

8. Schulz M, Hoffmann K, Weikert C, Nöthlings U, Schulze MB, Boeing $\mathrm{H}$. Identification of a dietary pattern characterized by high-fat food choices associated with increased risk of breast cancer: the European Prospective Investigation into Cancer and Nutrition (EPIC)-Potsdam Study. Br J Nutr. 2008; 100(5): 942-946, https://doi.org/10.1017/ S0007114508966149.

9. Szyfter K, Jarmuż M. Determination of genetic risk of cancer using the bleomycin test. Contemporary Oncology. 1999; 3(5): 188-190.

10. Chen YC, Hunter DJ. Molecular Epidemiology of Cancer. Onkologia po Dyplomie. 2005; 2(2): 36-45.

11. Arico M, et al. Clinical outcome of children with newly diagnosed Philadelphia chromosome-positive acute lymphoblastic leukemia treated between 1995 and 2005. J Clin Oncol. 2010; 28(31): 4755-61, https://doi.org/10.1200/JCO.2010.30.1325.

12. Monsalve J, Kapur J, Malkin D, Babyn PS. Imaging of Cancer Predisposition Syndromes in Children. RadioGraphics. 2011; (31): 263-280, https://doi.org/10.1148/rg.311105099.

13. Burger $M$, et al. Epidemiology and Risk Factors of Urothelial Bladder Cancer. European Urology. 2013; 63(2): 234-241, https://doi. org/10.1016/j.eururo.2012.07.033.

14. Bonfa R, Bonfa R, Furian R, Bonamigo R, Duro K, Zelmanowicz A. Early diagnosis of cutaneous melanoma: an observation in southern Brazil. An Bras Dematol. 2011; 86(2): 215-221.

15. Pepłońska B, Szeszenia-Dąbrowska N. Occupational Risk Factors for Breast Cancer in the Epidemiological Studies. Med Pr. 2001; 52(6): 483-495.

16. Szmigielski S. Risk of neoplastic diseases in conditions of exposure to power magnetic fields - epidemiological investigations. Med Pr. 2009; 60(3): 223-233.

17. Oeffinger KC, Hudson MM. Long-term complications following childhood and adolescent cancer: foundations for providing risk-based health care for survivors. Onkologia po Dyplomie. 2004; 1(5): 25-48.

18. Postrzech K, Welz K, Kopyra J, Reich A. Impact of Ultraviolet B Radiation on Stratum Corneum. Dermatol Rev. 2010; 97: 185-190. 
19. Batycka-Baran A, Kuczborska I, Szepietowski J. Vitamin D and malignant melanoma - review of the literature. Clin Dermatol. 2012; 14(1): 37-41.

20. Stawczyk M, Łakis A, Ulatowska A, Szczerkowska-Dobosz A. Evaluation and comparison of the risk of sunbathing addiction among selected population of women. Dermatol Rev. 2011; 98: 305-311.

21. Wolnicka-Głubisz A, Płonka PM. The Role of UV Radiation in etiopathogenesis of melanoma. Contemporary Oncology. 2007; 11(9): 419-429.

22. Bień S. Malignant Melanoma of Head and Neck. Otorynolaryngologia 2005; 4(3): 113-120.

23. Jen M, Murphy M, Grant-Kels J. Childhood melanoma. Clin Dermatol. 2009; 7: 29-536, https://doi.org/10.1016/j.clindermatol.2008.09.011.

24. Narbutt J, Lesiak A, Ekiert A, Sysa-Jędrzejowska A. Environmental factors in nonmelanoma skin cancer development. Polish J Environ Studies. 2005;14:545-550.

25. Lesiak A, Słowik-Rylska M, Kozłowski W, Sysa-Jędrzejowska A, Jochymski C, Rogowski-Tylman M, Narbutt J. Epidermal proliferation and intracellular adhesion impairment as one mode of action of ultraviolet-B radiation. Advances in Dermatology and Allergology. 2009; XXVI(4): 180-185.

26. Leon ME, Peruga A, McNeill A, Kralikova E, Guha N, Minozzi S, Espina C, Schüz J. European Code against Cancer, 4th Edition: Tobacco and cancer. Cancer Epidemiol. 2015; 39(1): 20-33. https://doi: 10.1016/j. canep.2015.06.001.

27. Carroll Chapman SL, Wu LT. E-cigarette prevalence and correlates of use among adolescents versus adults: a review and comparison. J Psychiatr Res. 2014; 54: 43-54. https://doi: 10.1016/j.jpsychires.2014.03.005

28. World Health Organization International Agency for Research on Cancer, Smokeless tobacco and some tobacco-specific N-nitrosamines. IARC Monogr Eval Carcinog. Risks Hum. 2007; 89: 1-592.

29. Diethelm PA, Farley TM. Refuting tobacco-industry funded research: empirical data shows decline in smoking prevalence following introduction of plain packaging in Australia. Tob Prev Cessation 2015; 1(6): 2459-3087. https://doi.org/10.18332/tpc/60650.

30. Vance RB. Common interests and common goals: achieving greater progress in preventive health through strategic collaborations. Onkologia po Dyplomie. 2004; 1(5): 5-6.

31. Podlodowska J, Szumiło J, Podlodowski W, Starosławska E, Burdan F. Epidemiology and Risk Factors of the Oral Carcinoma. Pol Merk Lek. 2012; XXXII(188): 135-137.

32. Stark MJ, Rohde K, Maher JE, et al. The impact of clean indoor air exemptions and preemption policies on the prevalence of a tobaccospecific lung carcinogen among nonsmoking bar and restaurant workers. Am J Public Health. 2007 August; 97(8): 1457-1463. https:// doi: 10.2105/AJPH.2006.094086.

33. Becher H, Belau M, Winkler V, Aigner A. Estimating lung cancer mortality attributable to second hand smoke exposure in Germany. Int J Public Health. 2018 Apr; 63(3): 367-375. https://doi: 10.1007/ s00038-017-1022-1.

34. Thomas JL, et al. Metabolites of a tobacco-specific lung carcinogen in children exposed to secondhand or thirdhand tobacco smoke in their homes. Cancer Epidemiol Biomarkers Prev. 2011 Jun; 20(6): 1213-21. https://doi: 10.1158/1055-9965.EPI-10-1027.

35. Cogliano VJ, Baan R, Straif K, et al. Preventable exposures associated with human cancers. J Natl Cancer Inst. 2011; 103(24): 1827-39. https:// doi: 10.1093/jnci/djr483.

36. Pollitt RA, Geller AC, Brooks DR, Johnson TM, Park ER, Swetter SM. Efficacy of Skin Self-Examination Practices for Early Melanoma Detection. Cancer Epidemiol Biomark Prev. 2009; 18(11): 3018-23, https://doi.org/10.1158/1055-9965.EPI-09-0310.

37. Boffetta P, Malhotra J. Impact of Heart Failure on Cancer Incidence: A Complicated Question. J Am Coll Cardiol. 2018; 71(14): 1511-1512. https://doi:10.1016/j.jacc.2018.02.015.

38. Adlard JW, Hume MJ. Cancer knowledge of the general public in the united kingdom: survey in a primary care setting and review of the literature. Clin Oncol. 2003; 15: 174-180.

39. Farvid MS, Cho E, Chen WY, Eliassen AH, Willett WC. Adolescent meat intake and breast cancer risk. Int J Cancer. 2015; 136(8): 19091920, https://doi.org/10.1002/ijc. 29218.

40. Chang JS, Straif K, Guha N. The role of alcohol dehydrogenase genes in head and neck cancers: a systematic review and meta-analysis of ADH1B and ADH1C. Mutagenesis 2012; 27(3): 275-86. https://doi: 10.1093/mutage/ger073.

41. Franceschi S, Bidoli E, Herrero R, Muñoz N. Comparison of cancers of the oral cavity and pharynx worldwide: etiological clues. Oral Oncol. 2000 Jan; 36(1): 106-15.
42. World Health Organization International Agency for Research on Cancer. Personal habits and indoor combustions. A review of human carcinogens. IARC Monogr. Eval. Carcinog. Risks Hum. 2012; 100: $1-538$.

43. Seouda M, Tjalmab WAA, Ronssec V. Cervical adenocarcinoma: Moving towards better prevention. Vaccine. 2011; 29: 9148-9158, https://doi.org/10.1016/j.vaccine.2011.09.115.

44. Kupczewska-Dobecka M. Assessment of Carcinogenicity of Formaldehyde Based on the Newest Literature Data. Med Pr. 2007; 58(6): 1-13.

45. Fung TT, Hu FB, Hankinson SE, Willett WC, Holmes MD. Lowcarbohydrate diets, dietary approaches to stop hypertension-style diets, and the risk of postmenopausal breast cancer. Am J Epidemiol. 2011; 174(6): 652-660, https://doi.org/10.1093/aje/kwr148.

46. O'Mahony M, Hegarty J. Help seeking for cancer symptoms: a review of the literature. Oncol Nurs Forum. 2009; 36(4): 178-84, https://doi. org/10.1188/09.ONF.E178-E184.

47. Chybicka A. Influence of mother's diet during pregnancy on cancer incidence in children. Prevention activities. Pol Med Rodz. 2004; 6(3): 1213-1215

48. Eyre H, et al. Preventing Cancer, Cardiovascular Disease, and Diabetes: a Common Agenda for the American Cancer Society, the American Diabetes Association, and the American Heart Association. Onkologia po Dyplomie. 2004; 1(5): 7-24.

49. Lajous M, Lazcano-Ponce E, Hernandez-Avila M, Willett W, Romieu I. Folate, vitamin B(6), and vitamin B(12) intake and the risk of breast cancer among Mexican women. Cancer Epidemiol Biomarkers Prev. 2006; 15(3): 443-8, https://doi.org/10.1158/1055-9965.EPI-05-0532.

50. Gil J, Stembalska A, Łaczmańska I, Sąsiadek M. Sporadic colorectal cancer - factors modulating individual susceptibility to cancer. Contemporary Oncol. 2010; 14(3): 211-216.

51. Neuhouser ML, Aragaki AK, Prentice RL, et al. Overweight, Obesity, and Postmenopausal Invasive Breast Cancer Risk: A Secondary Analysis of the Women's Health Initiative Randomized Clinical Trials. JAMA Oncol. 2015; 1(5): 611-621, https://doi.org/10.1001/jamaoncol.2015.1546.

52. Bracci PM. Obesity and pancreatic cancer: overview of epidemiologic evidence and biologic mechanisms. Mol Carcinog. 2012; 51(1): 53-63, https://doi.org/10.1002/mc.20778.

53. Przybylska D, Kurowska M, Przybylski P. Obesity and overweight in the adolescent population. Hygeia Public Health. 2012; 47(1): 28-35.

54. Peterson E, Prithwish D, Nuttall R. BMI, diet and female reproductive factors as risks for thyroid cancer: a systematic review. PLoS One. 2012; 7(1), https://doi.org/10.1371/journal.pone.0029177.

55. Szkaradkiewicz A. Microbes and oncogenesis. Contemporary Oncol. 2003; 7(2): 96-101.

56. González CA, Agudo A. Carcinogenesis, prevention and early detection of gastric cancer: where we are and where we should go. Int J Cancer. 2012; 130: 745-753, https://doi.org/10.1002/ijc.26430.

57. Dias EP, Rocha ML, Carvalho MO, Fonte de Amorim LM. Detection of Epstein-Barr virus in recurrent tonsillitis. Braz J Otorhinolaryngol. 2009; 75(1): 30-4.

58. Jemal A, Bray F, Center MM, Ferlay J, Ward E, Forman D. Global cancer statistics. CA Cancer J Clin. 2011; 61(2): 69-90, https://doi. org/10.3322/caac.20107.

59. Pierce ES. Could Mycobacterium avium subspecies paratuberculosis cause Crohn's disease, ulcerative colitis and colorectal cancer? Infect Agent Cancer. 2018 Jan 4; 13: 1 https://doi.org/10.1186/s13027-0170172-3.

60. Delbue S, Comar M, Ferrante P. Review on the role of the human Polyomavirus JC in the development of tumors. Infect Agent Cancer. 2017; 3(12): 10-20. doi: 10.1186/s13027-017-0122-0.

61. Maginnis MS, Atwood WJ. JC virus: an oncogenic virus in animals and humans? Semin Cancer Biol. 2009 Aug; 19(4): 261-9. doi: 10.1016/j. semcancer.2009.02.013.

62. Don S, et al. Clinical Cancer Advances 2016: Annual Report on Progress Against Cancer From the American Society of Clinical Oncology. JClin Oncol. Mar 20; 34(9): 987-1011. https://doi: 10.1200/JCO.2015.65.8427.

63. Pellegriti G, Frasca F, Regalbuto C, Squatrito S, Vigneri R. Worldwide Increasing Incidence of Thyroid Cancer: Update on Epidemiology and Risk Factors. J Canc Epidemiol. 2013 (2013): 10, http://dx.doi. org/10.1155/2013/965212.

64. Brito JP, Yarur AJ, Prokop LJ, McIver B, Murad MH, Montori VM. Prevalence of thyroid cancer in multinodular goiter versus single nodule: a systematic review and meta-analysis. Thyroid. 2013; 23(4): 449-455, https://doi.org/10.1089/thy.2012.0156. 